\title{
Surface Modification of the Biowaste for Purification of Wastewater Contaminated with Toxic Heavy Metals - Lead and Cadmium
}

\author{
Bindra Shrestha*, Jagjit Kour, Puspa Lal Homagai, Megh Raj Pokhrel, Kedar Nath Ghimire \\ Central Department of Chemistry, Tribhuvan University, Kathmandu, Nepal \\ Email: "binraghu@yahoo.com
}

Received April 2, 2013; revised May 12, 2013; accepted June 12, 2013

Copyright (C) 2013 Bindra Shrestha et al. This is an open access article distributed under the Creative Commons Attribution License, which permits unrestricted use, distribution, and reproduction in any medium, provided the original work is properly cited.

\begin{abstract}
The surface of a biowaste was modified by introduction of amino group for the purification of wastewater contaminated with heavy metals. In this study waste tea leaf was used as a biowaste which was an economic and efficient bioadsorbent. The aminated tea leaves were characterized by spectral and elemental analysis. The adsorption capacity of the surface modified biosorbent was studied as the function of solution $\mathrm{pH}$, concentration of metal ions and contact time of adsorption. The applicability of Langmuir isotherm was tested. The adsorption capacities were found to be $83.04 \mathrm{mg} / \mathrm{g}$ and $57 \mathrm{mg} / \mathrm{g}$ for $\mathrm{Pb}$ (II) and $\mathrm{Cd}$ (II), respectively. The biosorbent was regenerated by desorption of the metal loaded adsorbent with $0.1 \mathrm{M} \mathrm{HNO}_{3}$. These results showed that the aminated tea leaves may be an attractive alternative for treatment of wastewater contaminated with heavy metals.
\end{abstract}

Keywords: Bioadsorbent; Heavy Metals; Wastewater; Amination; Langmuir Isotherm

\section{Introduction}

There is a growing concern for the effective treatment of wastewater contaminated with heavy metals. Most of the heavy metals are highly toxic even in trace concentration [1]. Lead is one of the most toxic environmental pollutants. Its compounds are used in paints and ceramics. It is also used for the production of antiknock compounds like tetraethyl lead for addition to petrol. One of the major sources of the environmental contamination by lead is the exhaust gases generated from vehicles which mainly contain oxides, halides and alkyl compounds of lead. It causes kidney, liver and gastrointestinal damage, mental retardation in children. Cadmium is a nonbeneficial and non-essential element. It is also highly toxic metal. Its main sources are electroplating industries, pesticides, fertilizer and $\mathrm{Cd}-\mathrm{Ni}$ batteries. It causes renal disorder, Itai-Itai disease, bone marrow cancer and bronchitis [2]. These metals do not degrade into harmless end products during metabolism. They are accumulated in food chain - water-plants - animals - humans, causing the greatest threat to living organism [3]. So they must be removed from contaminated water prior to their discharge.

Most of the common methods used to remove heavy

"Corresponding author. metals from wastewater are chemical reduction followed by precipitation, membrane filtration, ion-exchange and adsorption onto activated carbon. Among these, adsorption by activated carbon has been used as an effective method to remove these heavy metals in trace concentration. However, the activated carbon is expensive and requires chelating agents to enhance its performance, thereby increasing treatment cost. For this reason, it is desirable to develop low cost and efficient adsorbent for removal of heavy metals from wastewater. Recently, adsorptions of metals by using bioadsorbents are in progress $[4,5]$. Different types of industrial and agricultural bio-wastes are investigated as bioadsorbent such as sugarcane bagasse [6], rice husk [7], olive stone [8], orange waste [9], used tea leaves [10], wheat straw [11], sea weeds [12], chitin and chitosan [13]. They are easily available, economically acceptable and chemically less polluting substances often with high affinity and binding capacity of metals.

In adsorption process, metal ions from solution are transported to the surface of the adsorbent and then attached due to the physical and chemical interaction between the metal ions and the functional groups on the surface of the adsorbent. Functional groups like amine, carboxyl, sulphonic, amide, phosphonic and so forth fa- 
cilitate the adsorption of metal ions [14,15]. In particular amino group onto an adsorbent has been found to be one of the most effective groups for adsorption of heavy metals from aqueous solution [16,17].

In present study, waste tea leaves have been chemically modified by grafting amine functional group onto the surface and used as biosorbent, although they have been used by earlier researchers in a less effective way $[18,19]$. It contains lignin $(28.70 \%)$, cellulose $(22.33 \%)$ and hemicelluloses (11.37\%). These natural polymers contain various functional groups like methoxy, alcoholic and phenolic hydroxyl groups, carboxyl, aldehyde, which make them suitable for adsorption of heavy metals [20]. These functional groups can be chemically modified to enhance the adsorption capacity of the biosorbent [21]. The aim of the present work was to introduce amino group on the surface of the biosorbent and to investigate adsorption properties of $\mathrm{Pb}$ (II) and $\mathrm{Cd}$ (II) onto the chemically modified biosorbent.

\section{Materials and Methods}

\subsection{Chemicals}

Stock solutions of $\mathrm{Pb}$ (II), Cd (II) were prepared by dissolving required amount of lead nitrate and cadmium nitrate in $0.1 \mathrm{M} \mathrm{HNO}_{3}$ to make $1000 \mathrm{mg} / \mathrm{L}$ solution. Working solutions of various concentrations were prepared from the stock solution by diluting with $0.1 \mathrm{M}$ $\mathrm{HNO}_{3}$. During the experiment, $\mathrm{pH}$ of the solution was adjusted using $0.1 \mathrm{M} \mathrm{HNO}_{3}$ and $0.1 \mathrm{M} \mathrm{NaOH}$. The $0.1 \mathrm{M}$ solution of 2-[4-(2-hydroxymethyl)-1-piperazinyl] ethanesulphonic acid [HEPES] was used as buffering agent. All of the chemicals used were of analytical grade and double distilled water was used wherever necessary for the experimental work.

\subsection{Preparation of the Adsorbent}

About $150 \mathrm{~g}$ waste tea leaves (TL) was washed with hot water and dried in an oven at $80^{\circ} \mathrm{C}$ for $24 \mathrm{hrs}$. The dried tea leaves was powdered and sieved to pass through the $212 \mu \mathrm{m}$ sieve. The sample was charred with concentrated sulphuric acid. The charred tea leaves was then washed several times with distilled water till neutrality and dried in an oven at $80^{\circ} \mathrm{C}$ for $24 \mathrm{hrs}$.

The charred sample was chlorinated with thionylchloride in presence of pyridine maintaining the temperature at $0^{\circ} \mathrm{C}$ and heated at $70^{\circ} \mathrm{C}$ for one and half hrs. The adsorbent was washed with distilled water several times and dried. This chlorinated sample was then mixed with ethylenediamine and sodium carbonate in presence of dimethylsulphoxide and heated at $70^{\circ} \mathrm{C}$ for six hrs. The aminated adsorbent was washed with $0.1 \mathrm{M} \mathrm{HCl}$ followed by distilled water till neutrality. Finally the sample was washed and dried in an oven at $80^{\circ} \mathrm{C}$ for $24 \mathrm{hrs}$. The prepared sample was called surface modified tea leaves (STL).

\subsection{Determination of Optimum pH for Sorption Study}

Adsorption of metals was studied as the function of $\mathrm{pH}$ keeping the concentration constant by batch adsorption test. $25 \mathrm{mg}$ of adsorbent was taken in adsorption bottles and $20 \mathrm{~mL}$ of $50 \mathrm{mg} / \mathrm{L}$ metal solution with $\mathrm{pH} 1$ to $\mathrm{pH} 7$ were added to each bottle. Metal solution with different $\mathrm{pH}$ was adjusted by drop wise addition of $0.1 \mathrm{M} \mathrm{HNO}_{3}$ and $0.1 \mathrm{M} \mathrm{NaOH}$ solution. The bottles were shaken for $24 \mathrm{hrs}$ in a mechanical shaker at $150 \mathrm{rpm}$ maintaining the temperature at $25^{\circ} \mathrm{C}$. After shaking, $\mathrm{pH}$ values of the solutions were monitored and the filtrates were analyzed to evaluate the residual concentration of metals.

\subsection{Adsorption Isotherm}

Adsorption isotherms were determined by taking $20 \mathrm{~mL}$ of metal solutions of various concentrations ranging from 25 to $800 \mathrm{mg} / \mathrm{L}$ maintaining the optimum $\mathrm{pH}$, in stoppered bottles containing $25 \mathrm{mg}$ of adsorbent in each. The bottles were vigorously shaken for $24 \mathrm{hrs}$ in a mechanical shaker at $150 \mathrm{rpm}$. The residual concentration of respective metal ions after adsorption was analyzed for metal concentration using Atomic Adsorption Spectrophotometer (Agilent technologies, AAS, model-240 FSAA, USA).

\subsection{Determination of Equilibrium Time}

To determine the equilibrium time of adsorbent, $25 \mathrm{mg}$ of the adsorbent was taken in stoppered bottles. Then 20 $\mathrm{mL}$ of $50 \mathrm{mg} / \mathrm{L}$ metal solutions were added to each bottle maintaining the optimum $\mathrm{pH}$ of 4 and 6 for $\mathrm{Pb}$ (II) and Cd (II) solutions, respectively. All the stoppered bottles were shaken in mechanical shaker. The stoppered bottles were taken out from the shaker after each predetermined intervals of time and analyzed for residual metal concentration.

\section{Results and Discussion}

\subsection{Characterization}

In this study, the surface of the bioadsorbent was modified to enhance the adsorption capacity [22,23]. The bioadsorbent after acid treatment gets exposed to its polymeric networks, which is easier for the further substitution of amino functional group. The adsorbent was then aminated with ethylenediamine. During amination it is supposed that the alcoholic and phenolic- $-\mathrm{OH}$ groups present in lignin, cellulose and hemicelluloses were substituted with amino groups. The reaction involved can be schematically represented as follows (Scheme 1): 


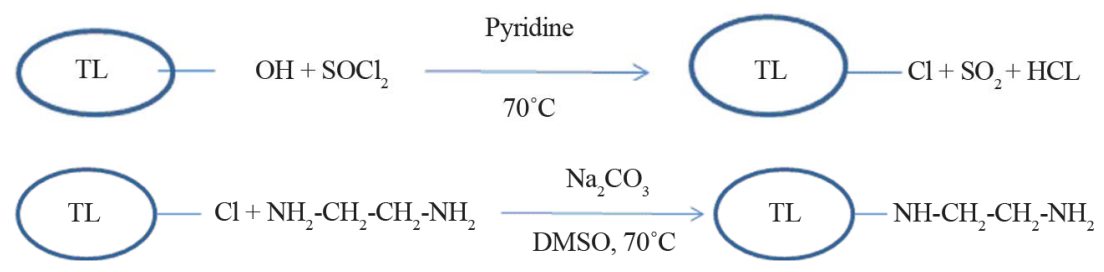

Scheme 1. Surface modification of tea leaves.

The N-atom of the amino group has been found to be more effective chelating group and it has greater tendency to donate lone pair of electrons for sharing with metal ions to form complexes. Hence there has been considerable interest for introduction of $\mathrm{N}$-containing functional group on the surface of the adsorbent to enhance the adsorption capacity. In this study amino functional groups were introduced on the surface of the bioadsorbent by using ethylenediamine. The surface modified bioadsorbent was characterized by scanning electron microscopy (SEM), fourior transform infrared spectroscopy (FTIR) and elemental analysis.

\subsubsection{SEM}

A scanning electron microscope (SEM) images were used to examine the surface morphologies of waste tea leaves before and after surface modification [24]. The images are given in Figures 1(a) and (b). The surface of tea leaves was found smooth and with uniform microporous structure which was changed after amination indicating the surface modification of the adsorbent. The surface of aminated tea leaves shows irregularly distributed pores which enhance the adsorption of metal ions.

\subsubsection{FTIR}

Each specific chemical bond often shows a unique energy absorption band in FTIR (Harric Scientific Corporation) analysis and it has been used as a useful tool to identify the presence of certain functional groups of the biosorbent $[25,26]$. The FTIR spectra of TL and STL are shown in Figure 2. The surface of adsorbent contains numerous functional groups so their spectra are complex. The broad and intense peaks around $3380 \mathrm{~cm}^{-1}$ in the spectrum of TL correspond to $\mathrm{OH}$ stretching vibration. It indicates the free $\mathrm{OH}$ group on the surface of the adsorbent and confirms the presence of alcohols and polyphenols in cellulose and lignin. The peak observed at 2923 $\mathrm{cm}^{-1}$ corresponds to $\mathrm{CH}$ stretching, the peaks around $1647 \mathrm{~cm}^{-1}$ is due to $\mathrm{C}=\mathrm{O}$ group and $1078 \mathrm{~cm}^{-1}$ due to $\mathrm{C}-\mathrm{O}$ stretching. The broad band around $600 \mathrm{~cm}^{-1}$ can be assigned to bending mode of aromatic compounds.

After chemical modification the spectrum exhibits some significant changes. The broad band ranging from $3085-3653 \mathrm{~cm}^{-1}$ may be due to overlapping of $\mathrm{OH}$ and $\mathrm{NH}$ stretching. Similarly the peaks at 1433 and $1094 \mathrm{~cm}^{-1}$ are due to $\mathrm{CH}$ bending and $\mathrm{CN}$ stretching respectively. It

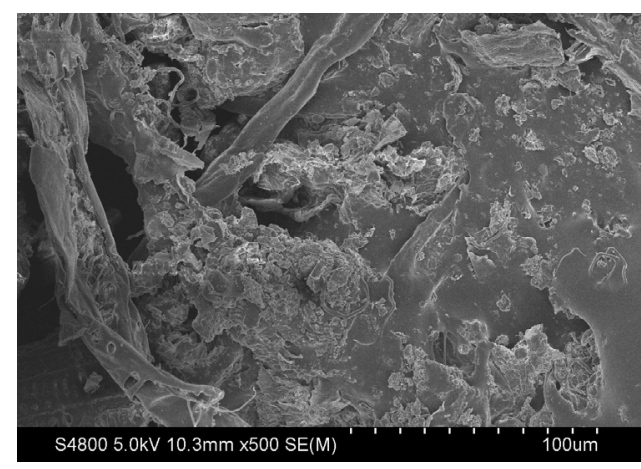

(a)

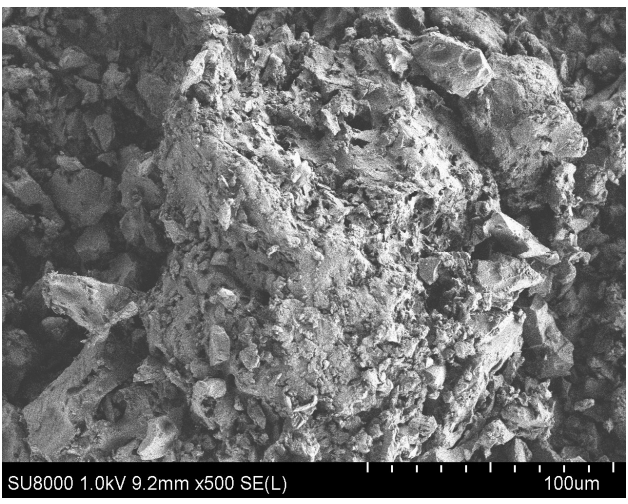

(b)

Figure 1. Scanning electron microscope (SEM) images 1(a) and 1(b) of tea leaves (TL) and surface modified tea leaves (STL), respectively.

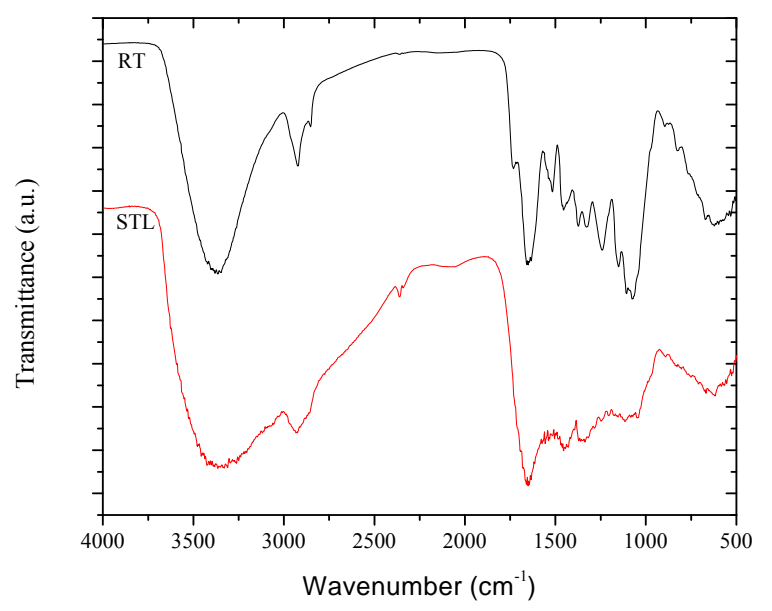

Figure 2. FTIR spectra of tea leaves (TL) and surface modified tea leaves (STL). 
indicates the introduction of amino group in STL.

The percentage of nitrogen in elemental analysis of TL was found to be $1.03 \%$, which was increased to $9.52 \%$ in STL, which supports the introduction of amine functional groups on the surface of biosorbent after chemical modification.

\subsection{Adsorption Test}

\subsubsection{Effect of $\mathrm{pH}$}

The $\mathrm{pH}$ of the solution affects the surface charge of the adsorbent and degree of ionization of the adsorbate, so it is an important factor for adsorption of metals from their solution [27]. Figure 3 shows the percentage adsorption of $\mathrm{Pb}$ (II) and $\mathrm{Cd}$ (II) as the function of equilibrium $\mathrm{pH}$. The adsorption percentage was calculated by using Equation (1). The metal adsorption by CATL was sensitive to $\mathrm{pH} 1$ to $\mathrm{pH}$. The figure indicates that the adsorption was found to increase up to maximum when $\mathrm{pH}$ was increased from 1 to 6 . The optimum $\mathrm{pH}$ for maximum uptake of $\mathrm{Pb}$ (II) and $\mathrm{Cd}$ (II) onto STL was found to be at 4 and 6 , respectively. The adsorption increases rapidly near the optimum $\mathrm{pH}$ range.

The increase of sorption capacity with increase of $\mathrm{pH}$ can be explained on the basis of surface functional charge of the adsorbent and degree of ionization. At low $\mathrm{pH}$ higher concentration of $\mathrm{H}^{+}$ions with high mobility compete with metal cations for adsorption on the same functional group. At higher $\mathrm{pH}$, concentration of $\mathrm{H}^{+}$ions decreases and solubility of metal ions also decreases which results in higher metal uptake. It was confirmed by the observation that the sharp increase in final $\mathrm{pH}$ of the solution at optimum $\mathrm{pH}$ at which maximum adsorption of metal has taken place.

\subsubsection{Effect of Initial Concentration of Metal Ions}

The adsorption capacity of an adsorbent can be evaluated with the help of adsorption isotherm. Adsorption capacity is the concentration of the metal ions on the adsorbent

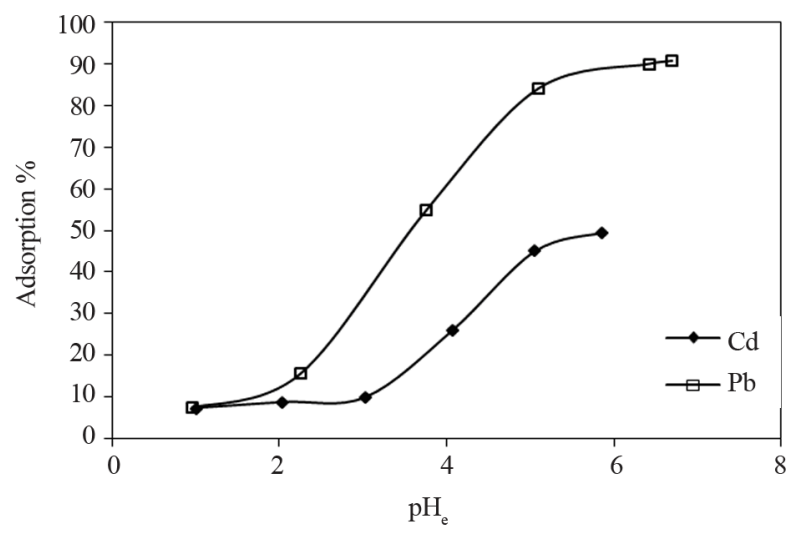

Figure 3. Adsorption of Pb (II) and Cd (II) onto STL as the function of equilibrium $\mathrm{pH}$. and can be calculated on the basis of mass balance equation as follows,

$$
q=\frac{C_{i}-C_{e}}{W} \times \frac{L}{1000}
$$

where $q$ is the amount of metal adsorbed per unit mass of adsorbent, $L$ is volume of test solution, $W$ is dry mass of the adsorbent, $C_{i}$ and $C_{e}$ are initial and final concentration of metal ions respectively. Figure 4 shows the adsorption isotherms for $\mathrm{Pb}$ (II) and $\mathrm{Cd}$ (II) onto the STL. The adsorption of metal ions increases with the increase in equilibrium concentration of metal ions. Eventually, the adsorption is limited by the fixed number of active sites of the adsorbent and a plateau of isotherm is obtained. This is because, at low concentration of metal ions the active sites of adsorbent are sufficiently available but at high concentration the active sites become fewer as compared to the metal ions. Hence at high metal concentration, adsorption amount becomes independent upon the initial concentration of metal ions [28,29].

The adsorption isotherms were evaluated using the linearized Langmuir model by,

$$
\frac{C_{e}}{q_{e}}=\frac{1}{q_{m} b}+\frac{C_{e}}{q_{m}}
$$

where $C_{e}(\mathrm{mg} / \mathrm{L})$ is equilibrium concentration of metal ions, $q_{e}(\mathrm{mg} / \mathrm{L})$ is the amount of metal ions adsorbed per $\mathrm{g}$ of adsorbent, $q_{m}(\mathrm{mg} / \mathrm{g})$ is the maximum adsorption capacity and $b(\mathrm{~L} / \mathrm{mg})$ is the binding constant. Langmuir parameters $q_{m}$ and $b$ were calculated from the plot of $C_{e} / q_{e}$ versus $\mathrm{C}_{e}$. Langmuir parameters and correlation coefficients are given in Table 1. The high value of Langmuir correlation coefficient confirmed that the Langmuir isotherm model is best fitted. The maximum adsorption capacities of experimental results shown in Figure 4 are 83.04 and 57 for $\mathrm{Pb}$ (II) and Cd (II), respectively. It showed that the active sites of the bioadsorbent STL are constant and independent of the concentration of metal ions. The values of $b$ are indicative of the affinity of the adsorbent for the metal ions.

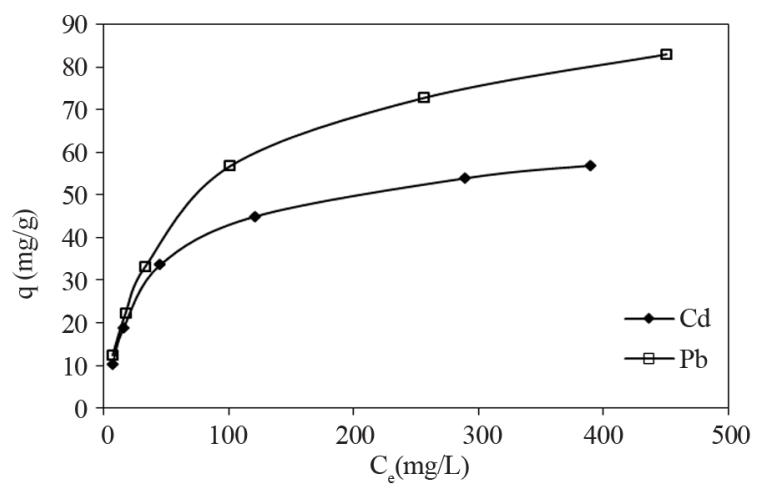

Figure 4. Effect of concentration on adsorption of $\mathrm{Pb}$ (II) and Cd (II) onto STL. 
Table 1. Langmuir adsorption isotherm model parameters and experimental $\boldsymbol{q}_{\mathrm{max}}$.

\begin{tabular}{ccccc}
\hline Metal ions & $\begin{array}{c}q_{m} \text { (expt.) } \\
(\mathrm{mg} / \mathrm{g})\end{array}$ & $\begin{array}{c}q_{m}(\text { graph }) \\
(\mathrm{mg} / \mathrm{g})\end{array}$ & $b(\mathrm{~L} / \mathrm{mg})$ & $\mathrm{R}^{2}$ \\
\hline $\mathrm{Pb}(\mathrm{II})$ & 100 & 83.04 & 0.0060 & 0.997 \\
$\mathrm{Cd}(\mathrm{II})$ & 62.5 & 57 & 0.0099 & 0.999 \\
\hline
\end{tabular}

The theoretical maximum adsorption capacity $\mathrm{q}_{\mathrm{m}}$ based on the Langmuir adsorption equation as shown in Figure 5 was determined to be 100 and $62.5 \mathrm{mg} / \mathrm{g}$ for Pd (II) and $\mathrm{Cd}$ (II), respectively are given in Table 1.These values are comparable with the experimental results suggesting that $\mathrm{Pb}$ (II) and $\mathrm{Cd}$ (II) can be effectively sequestered using STL.

\subsubsection{Effect of Contact Time}

Figure 6 represents the sorption kinetics of $\mathrm{Pb}$ (II) and Cd (II) onto STL as the function of time at an initial concentration of $50 \mathrm{mg} / \mathrm{L}$ solution. The concentration of metal ions was analyzed at optimum $\mathrm{pH}$ in a regular interval of time by AAS. Initially metal ions were rapidly adsorbed with increasing time and subsequently it became slow until a steady state condition was attained. The optimum time for adsorption of $\mathrm{Cd}$ (II) was around $100-120$ min and for $\mathrm{Pb}$ (II) it was around $150-170$ min.

To study the kinetics of the adsorption process, pseudofirst and pseudo-second order kinetic models have been used. The pseudo-first order kinetic model was proposed by Lagergren and rate constant is determined by Equation (3).

$$
\log \left(q_{e}-q_{t}\right)=\log q_{e}-\frac{K_{1}}{2.302} t
$$

where $q_{e}$ and $q_{t}$ are the amount of adsorbed metal ions $(\mathrm{mg} / \mathrm{g})$ at equilibrium and at any time $t(\mathrm{~min})$, respectively and $K_{1}$ is the rate constant of pseudo first order adsorption $\left(\mathrm{min}^{-1}\right)$. The adsorption rate constant, $K_{1}$ and equilibrium adsorption capacity were calculated from the slope and intercepts of plots of $\log \left(q_{e}-q_{t}\right)$ versus $t$, along with correlation coefficients $\mathrm{R}^{2}$ (not shown). The results indicated that the adsorption of $\mathrm{Pb}$ (II) and $\mathrm{Cd}$ (II) on STL did not follow the pseudo-first order kinetic model.

The kinetic study of adsorption onto STL was analyzed using pseudo-second order kinetics model given by Ho \& McKay [30]. It can be represented in its integrated form as shown in Equation (4)

$$
\frac{t}{q_{t}}=\frac{1}{K_{2} q_{e}^{2}}+\frac{t}{q_{e}}
$$

where $q_{t}(\mathrm{mg} / \mathrm{g})$ is the amount adsorbed at time $t(\mathrm{~min})$ and $K_{2}(\mathrm{~g} / \mathrm{mg} / \mathrm{min})$ is rate constant of pseudo-second or- der kinetic adsorption. The plot of $t / q_{t}$ versus $t$ in Figure 7 gives $K_{2}$ and $q_{e}$ values as given in Table 2 . The correlation coefficient $R^{2}$ value is near unity, which shows that the pseudo second order model can be applied for the adsorption of $\mathrm{Pb}$ (II) and Cd (II) onto STL and also confirmed the chemisorptions of metal ions [31].

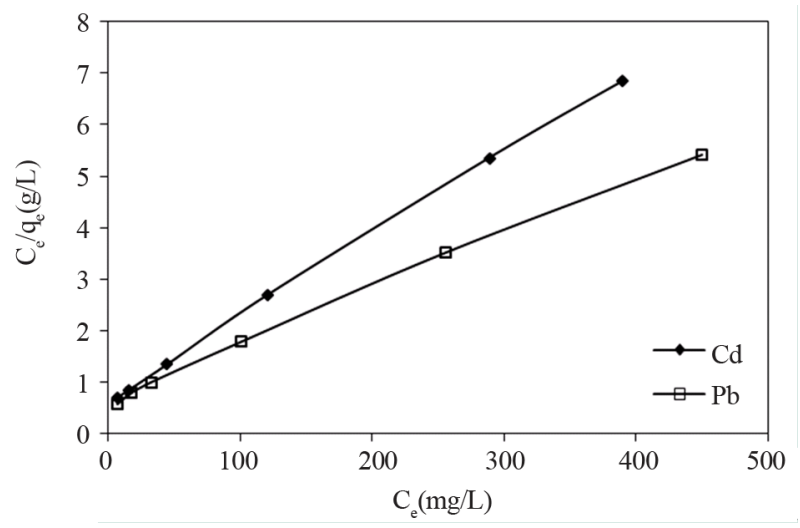

Figure 5. Langmuir plot for adsorption of $\mathrm{Pb}$ (II) and $\mathrm{Cd}$ (II) onto STL.

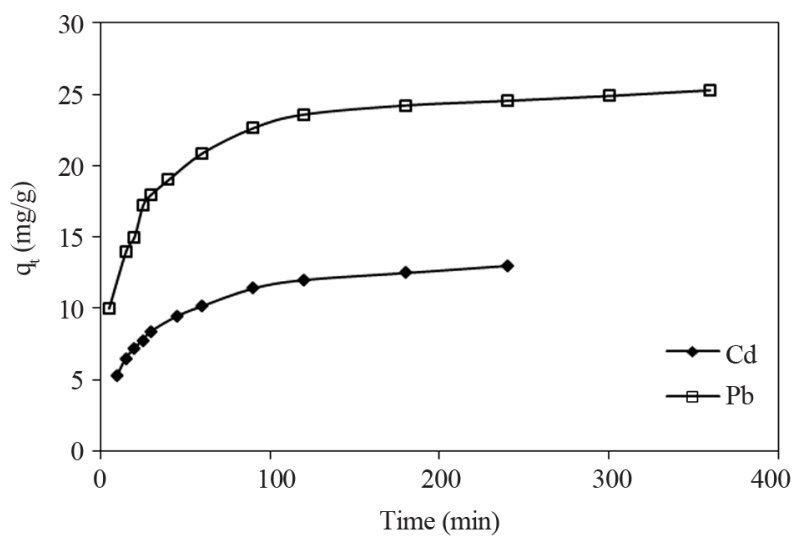

Figure 6. Adsorption kinetics of $\mathrm{Pb}$ (II) and Cd (II) onto STL.

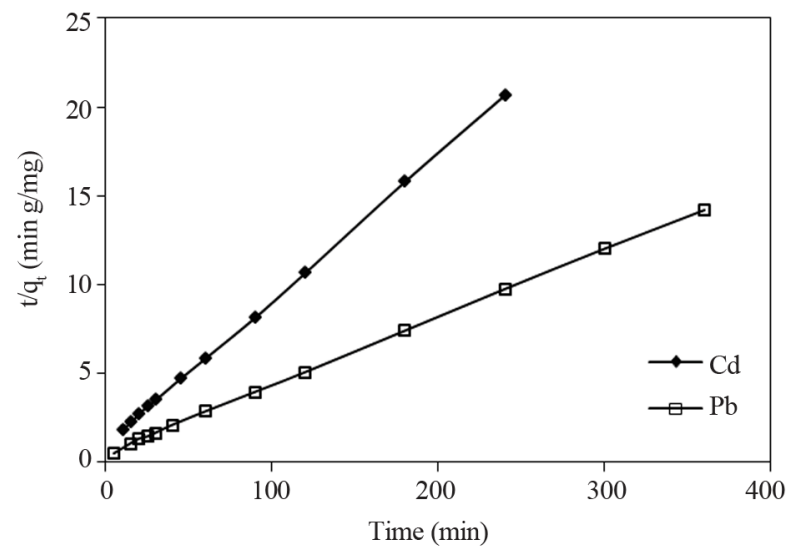

Figure 7. Pseudo-second order kinetic model for adsorption of Pb (II) and Cd (II) onto STL. 
Table 2. Pseudo-second order kinetics for adsorption of $\mathbf{P b}$ (II) and Cd (II) onto STL.

\begin{tabular}{ccc}
\hline Metal ions & $K_{2}(\mathrm{~g} / \mathrm{mg} / \mathrm{min})$ & $\mathrm{R}^{2}$ \\
\hline $\mathrm{Pb}(\mathrm{II})$ & 0.0028 & 0.999 \\
$\mathrm{Cd}(\mathrm{II})$ & 0.0060 & 0.999 \\
\hline
\end{tabular}

\subsection{Desorption}

The possibility of regeneration of the bioadsorbent and recovery of the metal ions can be explored by using desorption study. Desorption was carried out by using batch experimental method. In this study, the adsorbent was regenerated by using $0.1 \mathrm{M} \mathrm{HCl}, 0.1 \mathrm{M} \mathrm{HNO}_{3}$ and $0.1 \mathrm{M}$ $\mathrm{NaOH}$. Among these, the $0.1 \mathrm{M} \mathrm{HNO}_{3}$ was found more effective. After treatment of the metal adsorbed biosorbent with $0.1 \mathrm{M} \mathrm{HNO}_{3}$, the extent of desorption was found $93 \%$. Figure 8 shows the sorption capacity of the biosorbent for Cd (II) in six successive cycles. In the first sorption cycle the adsorption capacity was found to be 40 $\mathrm{mg} / \mathrm{g}$ for Cd (II), which was decreased to $36 \mathrm{mg} / \mathrm{g}$ in the second cycle. However the adsorption capacity remained relatively constant in subsequent cycles. The adsorption capacity attained was $34 \mathrm{mg} / \mathrm{g}$ in sixth cycle, indicating that the metal loaded bioadsorbent can be successfully regenerated using $0.1 \mathrm{M} \mathrm{HNO}_{3}$. This could be due to the fact that the surface modification increases the chemical stability of the adsorbent and especially decreases the solubility in acids. Evidently the adsorbent can be used repeatedly for metal adsorption from aqueous solution. After desorption the metals can be extracted from the liquid phase.

\section{Conclusion}

A new and efficient bioadsorbent has been investigated from the present investigation. Amine functional group was successfully introduced onto the surface of the biosorbent by using ethylenediamine. The adsorbent was characterized by elemental analysis, SEM and FTIR. The adsorption capacity of the biosorbent was found to increase with increasing $\mathrm{pH}$ upto the optimum $\mathrm{pH}$. Adsorption studies were well fitted with Langmuir model. The higher value of correlation coefficient was obtained using pseudo-second order kinetic model, indicating that the metal removal process followed the pseudo-second order rate expression. The maximum loading capacity for $\mathrm{Pb}$ (II) and Cd (II) onto the STL was found to be 83.04 and $57 \mathrm{mg} / \mathrm{g}$, respectively. After adsorption, the bioasorbent was successfully regenerated by using $0.1 \mathrm{M} \mathrm{HNO}_{3}$. These experimental results revealed that the surface modified aminated tea leaves (STL) can be used as an efficient bioadsorbent for the removal of $\mathrm{Pb}$ (II) and $\mathrm{Cd}$ (II) from their aqueous solution.

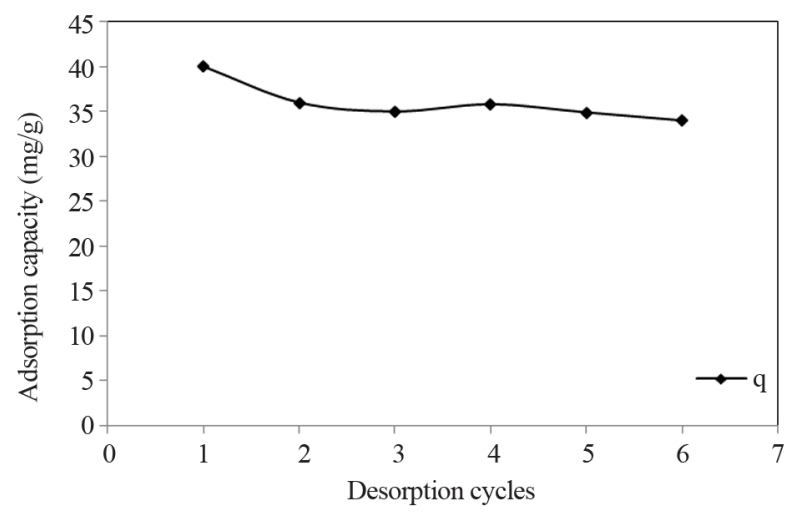

Figure 8. Reuse of regenerated STL for adsorption of Cd (II).

\section{Acknowledgements}

One of the authors, B. Shrestha, gratefully acknowledges National Academy of Science and Technology (NAST), Nepal, for providing $\mathrm{Ph}$. D. fellowship to carry out this research work.

\section{REFERENCES}

[1] V. M. Nurchi and I. Villaescusa, "Agricultural Biomasses as Sorbents of Some Trace Metals," Coordination Chemistry Review, Vol. 252, No. 10-11, 2008, pp. 1178-1188. doi:10.1016/j.ccr.2007.09.023

[2] S. Babel and T. A. Kurniawan, "Low Cost Adsorbents for Heavy Metals Uptake from Contaminated Water: A Review," Journal of Hazardous Materials, Vol. 97, No. 1-3, 2003, pp. 219-243. doi:10.1016/S0304-3894(02)00263-7

[3] J. C. Igwe and A. A. Abia, "A Bioseparation Process for Removing Heavy Metals from Wastewater Using Biosorbents-Review," African Journal of Biotechnology, Vol. 5, No. 12, 2006, pp. 1167-1179.

[4] B. Volesky and Z. R. Holan, "Biosorption of Heavy Metals," Biotechnology Progress, Vol. 11, No. 3, 1995, pp. 235-250. doi:10.1021/bp00033a001

[5] N. Das, R. Vimala and P. Karthika, "Biosorption of Heavy Metals-An Overview," Indian Journal of Biotechnology, Vol. 7, 2008, pp. 159-169.

[6] P. L. Homagai, K. N. Ghimire and K. Inoue, "Preparation and Characterization of Charred Xanthated Sugarcane Bagasse for the Separation of Heavy Metals from Aqueous Solutions," Separation Science and Technology, Vol. 46, No. 2, 2011, pp. 330-339. doi:10.1080/01496395.2010.506903

[7] U. Kumar and M. Bandyopadhyay, "Sorption of Cadmium from Aqueous Solution Using Pretreted Rice Husk," Bioresource Technology, Vol. 97, No. 1, 2006, pp. 104-109. doi:10.1016/j.biortech.2005.02.027

[8] G. Blazquez, F. Hernainz, M. Calero and L. F. Ruiz-Nunez, "Removal of Cadmium Ions with Olive Stone: The Effect of Some Parameters," Process Biochemistry, Vol. 40, No. 8, 2005, pp. 2649-2654. 
doi:10.1016/j.procbio.2004.11.007

[9] B. K. Biswas, K. Inoue, K. N. Ghimire, H. Harada, K. Ohto and H. Kawakita, "Removal and Recovery of Phosphorus from Water by means of Adsorption onto Orange Waste Gel Loaded with Zirconium," Bioresource Technology, Vol. 99, No. 18, 2008, pp. 8685-8690. doi:10.1016/j.biortech.2008.04.015

[10] T. A. Islam, H. A. Begum, M. A. Hossain and M. T. Rahman, "Removal of $\mathrm{Pb}$ (II) from Aqueous Solution by Sorption on Used Tealeaves," Journal of Bangladesh Academy of Sciences, Vol. 33, No. 2, 2009, pp. 167-178.

[11] S. Chen, Q. Yue, B. Gao and X. Xu, "Equilibrium and Kinetic Adsorption Study of the Adsorptive Removal of Cr (VI) Using Modified Wheat Residue," Journal of Colloid and Interface Science, Vol. 349, No. 1, 2010, pp. 256-264. doi:10.1016/j.jcis.2010.05.057

[12] K. N. Ghimire, K. Inoue, K. Ohto and T. Hayashida, "Adsorptive Separation of Metallic Pollutants onto Waste Seaweeds, Porphyra yezoensis and Ulva japonica," Separation Science and Technology, Vol. 42, No. 9, 2007, pp. 2003-2018. doi:10.1080/15363830701313461

[13] K. Vijayarhavan, K. Palanivelu and M. Veian, "Biosorption of Copper (II) and Cobalt (II) from Aqueous Solutions by Crab Shell Particles," Bioresource Technology, Vol. 97, No. 12, 2006, pp. 1411-1419. doi:10.1016/j.biortech.2005.07.001

[14] G. Sun and W. Shi, "Sunflower Stalks as Adsorbents for the Removal of Metal Ions from Wastewater," Industrial \& Engineering Chemistry Research, Vol. 37, No. 4, 1998, pp. 1324-1328. doi:10.1021/ie970468j

[15] K. N. Ghimire, K. Inoue, H. Yamaguchi, K. Makino and T. Miyajima, "Adsorptive Separation of Arsenate and Arsenite Anions from Aqueous Medium by Using Orange Waste," Water Research, Vol. 37, No. 20, 2003, pp. 49454953. doi:10.1016/j.watres.2003.08.029

[16] S. Deng, R. Bai and J. P. Chen, "Aminated Polyacrylonitrile Fibers for Lead and Copper Removal," Langmuir, Vol. 19, No. 12, 2003, pp. 5058-5064. doi:10.1021/la034061x

[17] S. Deng, R. Bai and J. P. Chen, "Behaviors and Mechanisms of Copper Adsorption on Hydrolysed Polyacrylonitrile Fibers," Journal of Colloid and Interface Science, Vol. 260, No. 2, 2003, pp. 265-272. doi:10.1016/S0021-9797(02)00243-6

[18] A. H. Mahvi, D. Naghipour and F. Vaezi, "Teawaste as an Adsorbent for Heavy Metal Removal from Industrial Wastewaters," American Journal of Applied Sciences, Vol. 2, No. 1, 2005, pp. 372-375. doi:10.3844/ajassp.2005.372.375

[19] W. S. Wan Ngah and M. A. K. M. Hanafiah, "Removal of Heavy Metal Ions from Wastewater by Chemically Modified Plant Wastes as Adsorbents: A Review," Bioresource Technology, Vol. 99, No. 10, 2008, pp. 3935-3948. doi:10.1016/j.biortech.2007.06.011

[20] M. C. Basso, E. G. Cerrella and A. L. Cukierman, "Lig- nocellulosic Materials as Potential Biosorbents of Trace Toxic Metals from Wastewater," Industrial \& Engineering Chemistry Research, Vol. 41 No. 15, 2002, pp. 35803587. doi:10.1021/ie020023h

[21] S. Chen, Q. Yue, B. Gao and X. Xu, "Equilibrium and Kinetic Adsorption Study of the Adsorptive Removal of Cr (VI) Using Modified Wheat Residue," Journal of Colloid and Interface Science, Vol. 349, No. 1, 2010, pp. 256-264. doi:10.1016/i.jcis.2010.05.057

[22] S. Deng and Y. P. Ting, "Fungal Biomass with Grafted Poly(acrylic acid) for Enhancement of Cu (II) and Cd (II) Biosorption," Langmuir, Vol. 21, No. 13, 2005, pp. 59405948. doi:10.1021/la047349a

[23] K. J. Tiemann, G. Gamez, K. Dokken, J. G. Parsons and J. L. Gardea-Torresdey, "Chemical Modification and X-Ray Absorption Studies for Lead (II) Binding by Medicago sativa (alfalfa) Biomass," Microchemical Journal, Vol. 71, No. 2-3, 2002, pp. 287-293. doi:10.1016/S0026-265X(02)00021-8

[24] N. Sankaramakrishnan and R. Sanghi, "Preparation and Characterization of a Novel Xanthated Chitosan," Carbohydrate Polymers, Vol. 66, No. 2, 2006, pp. 160-167.

[25] R. L. Shriner, C. K. F. Hermann, T. C. Morill, D. Y. Curtin and R. C. Fuson, "The Systematic Identification of Organic compounds," 7th Edition, Wiley, New York, 1998.

[26] P. Pavasant, R. Apiratikul, V. Sungkhum , P. Suthiparinyanont, S. Wattanachira and T. F. Marhaba, "Biosorption of $\mathrm{Cu}^{2+}, \mathrm{Cd}^{2+}, \mathrm{Pb}^{2+}$ and $\mathrm{Zn}^{2+}$ Using Dried Marine Green Macroalga Caulerpa Lentillifera," Bioresource Technology, Vol. 97, No. 18, 2006, pp. 2321-2329. doi:10.1016/j.biortech.2005.10.032

[27] A. W. Krowiak, R. G. Szafran and S. Modlski, "Biosorption of Heavy Metals from Aqueous Solutions onto Peanut Shell as a Low-Cost Biosorbent," Desalination, Vol. 265, No. 1-3, 2011, pp. 126-134. doi:10.1016/j.desal.2010.07.042

[28] R. Ayyappan, A. C. Sophia, K. Swaminathan and S. Sandhya, "Removal of $\mathrm{Pb}$ (II) from Aqueous Solution Using Carbon Derived from Agricultural Wastes," Process Biochemistry, Vol. 40, No. 3-4, 2005, pp. 293-1299. doi:10.1016/j.procbio.2004.05.007

[29] P. Miretzky, C. Munoz and A. C. Chavez, "Experimental Binding of Lead to a Low Cost Biosorbent: Nopal (Opuntia streptacantha)," Bioresource Technology, Vol. 99, No. 5, 2008, pp. 1211-1217. doi:10.1016/j.biortech.2007.02.045

[30] Y. S. Ho and G. McKay, "Pseudo-Second Order Model for Sorption Processes," Process Biochemistry, Vol. 34, No. 5, 1999, pp. 451-465. doi:10.1016/S0032-9592(98)00112-5

[31] D. Wankasi, J. M. Horsfall and A. I. Spiff, "Sorption Kinetics of $\mathrm{Pb}^{2+}$ and $\mathrm{Cu}^{2+}$ Ions from Aqueous Solution by Nipah palm (Nypa fruticans Wurmb) Shoot Biomass," Electronic Journal of Biotechnology, Vol. 9, No. 5, 2006, pp. 587-592. doi:10.2225/vol9-issue5-fulltext-5 